Article

\title{
The Mitochondrial Pentatricopeptide Repeat Protein PPR18 Is Required for the cis-Splicing of nad4 Intron 1 and Essential to Seed Development in Maize
}

\author{
Rui Liu ${ }^{1}$, Shi-Kai Cao ${ }^{1}{ }^{\circledR}$, Aqib Sayyed ${ }^{1}$, Chunhui Xu ${ }^{1}$, Feng Sun ${ }^{1}$, Xiaomin Wang ${ }^{2}$ and \\ Bao-Cai Tan ${ }^{1, *}$ \\ 1 Key Laboratory of Plant Development and Environment Adaptation Biology, Ministry of Education, \\ School of Life Sciences, Shandong University, Qingdao 266237, China; liuxiaoshuang_6@163.com (R.L.); \\ caoshk5233@163.com (S.-K.C.); aqib.sayyed@yahoo.com (A.S.); chunhuixu@sdu.edu.cn (C.X.); \\ epusun@sdu.edu.cn (F.S.) \\ 2 Key Laboratory of Cell Activities and Stress Adaptations, Ministry of Education, School of Life Sciences, \\ Lanzhou University, Lanzhou 730000, China; wangxiaomin@lzu.edu.cn \\ * Correspondence: bctan@sdu.edu.cn
}

Received: 10 May 2020; Accepted: 2 June 2020; Published: 5 June 2020

\begin{abstract}
Pentatricopeptide repeat (PPR) protein comprises a large family, participating in various aspects of organellar RNA metabolism in land plants. There are approximately 600 PPR proteins in maize, but the functions of many PPR proteins remain unknown. In this study, we defined the function of PPR18 in the cis-splicing of nad4 intron 1 in mitochondria and seed development in maize. Loss function of PPR18 seriously impairs embryo and endosperm development, resulting in the empty pericarp (emp) phenotype in maize. PPR18 encodes a mitochondrion-targeted P-type PPR protein with 18 PPR motifs. Transcripts analysis indicated that the splicing of nad 4 intron 1 is impaired in the ppr 18 mutant, resulting in the absence of nad 4 transcript, leading to severely reduced assembly and activity of mitochondrial complex I and dramatically reduced respiration rate. These results demonstrate that PPR18 is required for the cis-splicing of nad 4 intron 1 in mitochondria, and critical to complex I assembly and seed development in maize.
\end{abstract}

Keywords: PPR protein; mitochondrial complex I; nad4; RNA splicing; seed development; maize

\section{Introduction}

Mitochondria are originated from $\alpha$-proteobacteria ancestors via endosymbiosis. During evolution, the majority of the bacterial ancestral genes from mitochondrial genome have been lost or transferred to host nucleus [1]. In angiosperms, mitochondrial genomes contain up to 60 genes, which are involved in biogenesis of respiratory complex subunits, ribosomal proteins, ribosomal RNAs (rRNAs), and transfer RNAs (tRNAs) [2,3]. Maize mitochondrial genome contains 58 identified genes that encode 22 proteins of the electron transport chain, 9 ribosomal proteins, a maturase (MatR), a transporter protein (MttB), 3 ribosomal RNAs (5S, 18S, and 26S), and 21 tRNAs [4].

Mature mitochondrial transcripts undergo extensive post-transcriptional processing events, among which the most reported are RNA editing and RNA splicing [5-7]. In flowering plants, RNA editing usually alters cytidine to uridine through a deamination reaction in mitochondria and plastids and RNA splicing is a processing event in which noncoding segments (intron) of precursor RNA are removed and coding sequences are joined. Based on the distinctive structures, introns are divided into two families, group I and group II [4,8]. In flowering plants, most of organellar transcripts contain group II introns with conserved secondary structure, consisting of six domains extending from a central hub [9]. In bacteria, the splicing of a group II intron is self-facilitated by its cognate maturase 
encoded in the intron domain IV [10], but in plants, nearly all introns lost the maturase gene with only one intron maturase gene (matK) remains in the plastid genome and one mat $R$ gene in the mitochondrial genome [11,12]. Instead, four maturase genes (nMat1 to 4) are found in the nuclear genome in Arabidopsis [13-15]. Besides, numerous additional nucleus-encoded splicing co-factors have been reported to be involved in the splicing of organellar introns, such as the chloroplast RNA splicing and ribosome maturation (CRM) domain-containing proteins [16,17], RNA helicase [18,19], mitochondrial transcription termination factors (mTERF) [20,21], plant organellar RNA recognition (PORR) domain proteins [22,23], regulator of chromosome condensation (RCC1) domain proteins [24], and the pentatricopeptide repeat (PPR) proteins $[5,25,26]$.

PPR proteins are a large family of RNA binding proteins, with more than 400 members in angiosperms [5,27]. PPR proteins contain multiple 35-amino-acid tandem repeats and each repeat forms a helix-loop-helix structure. Based on domain constitution, PPR proteins are divided into PLS (repeat P-L-S motif)-class proteins and P-class proteins [27]. The PLS-subclass PPR proteins contain characteristic triplets of $\mathrm{P}, \mathrm{L}$, and $\mathrm{S}$ motifs with additional $\mathrm{E}, \mathrm{E}+, \mathrm{DYW}$, or other domains at the C-terminus, whereas the P-subclass PPR proteins contain arrays of only P motifs [5]. The PLS-class PPR proteins are implicated in the C-to-U RNA editing that in most cases is to restore the evolutionary conserved amino acids [28]. Functions of the P-subclass PPR proteins are diverse, which includes RNA cleavage, RNA splicing, RNA stabilization and maturation, and translation initiation [5]. Most PPR proteins are localized in mitochondria or chloroplasts. They bind RNA in a sequence specific manner that one PPR motif binds to one nucleotide of the target RNA. The recognition nucleotides were determined by the different combinations of the amino acid residues at position 5th and 35th of each PPR repeat, which is known as the PPR codes [29-31]. In plant mitochondria, most of group II introns are present in genes that code for subunits of mitochondrial complex I. In maize mitochondria, out of 22 identified group II introns, 19 resides in nad1, nad2, nad4, nad5, and nad7 transcripts, while 3 in $r p s 3, c o x 2$, and $c c m F c$ transcripts [32,33]. Accurate splicing of these group II introns is critical to mitochondrial function and biogenesis, which is important for plant growth and development. For instance, EMP11 and DEK2 are involved in the splicing of nad1 introns, and the loss of function mutation of Emp11 and Dek2 affects the assembly of complex I with severely arrested embryo and endosperm development [34,35]. EMP10, EMP12, EMP16, DEK37, and PPR20 are responsible for the splicing of nad2 introns in maize. These mutations result in a loss of mitochondrial complex I assembly and activity, impairing the mitochondrial function and embryogenesis and endosperm development [25,36-39].

In this study, we characterized a maize seed mutant ppr18, which exhibits arrested embryo and endosperm development phenotype. PPR18 encodes a mitochondrion-targeted P-type PPR protein with 18 PPR motifs. The loss of PPR18 function leads to the splicing deficiency of nad4 intron 1, severely reduced assembly and activity of mitochondrial complex I, resulting in the impairment of mitochondrial function and seed development in maize.

\section{Results}

\subsection{PPR18 Is a Mitochondrion-Localized P-Type PPR Protein}

PPR18 (GRMZM2G438456) is an intronless gene, encoding an $85 \mathrm{kDa}$ protein with 768 amino acid residues (Figure 1A). Motif prediction analysis by algorithm TPRpred (http://tprpred.tebingen. mpg.de/tprpred) revealed that PPR18 contained 18 tandemly repeated PPR motifs without any other domains, suggesting that PPR18 is a canonical P-type PPR protein (Figure 1A,B). A phylogenetic analysis based on the maize PPR18 and its homologous proteins revealed extensive conservation in the sequences in both monocots and dicots (Figure S1). Most of PPRs are localized in organelles, either chloroplasts or/and mitochondria, except GRP23 and PNM1, which both have nucleus localized signals $[5,40,41]$. To determine the subcellular localization of PPR18, the 550 amino acid residues of the N-terminal PPR18 were fused to the green fluorescent protein (GFP) in the binary vector pGWB5, 
then transiently expressed in the tobacco leaves via Agrobacterium EHA105 infiltration. Confocal laser-scanning microscopy revealed that the strong green fluorescence signals of PPR $18^{\mathrm{N} 550}-\mathrm{GFP}$ are merged with the red signals of MitoTracker (Figure 1C), indicating that PPR18 is localized in mitochondria.

A

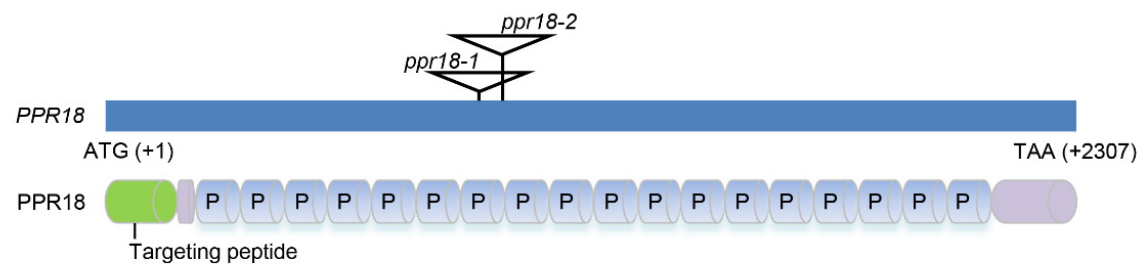

B

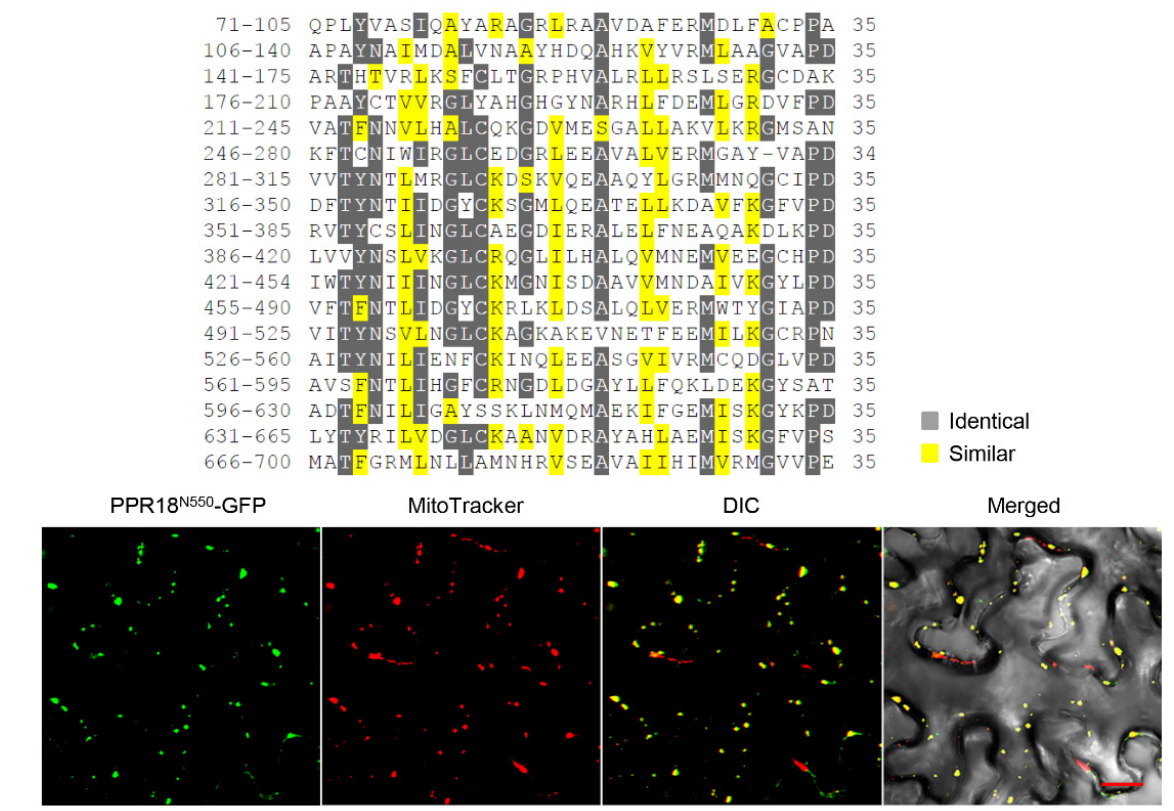

Figure 1. PPR18 is a mitochondrion-localized P-type pentatricopeptide repeat (PPR) protein. (A) Schematic illustrating the genomic structure and protein structure of PPR18. The locations of the $M u$ insertions are marked with triangles in two independent alleles. P, P-type PPR motif. (B) Alignment analysis of 18 PPR motifs in PPR18 protein. Identical amino acids are highlighted in dark gray and similar ones in yellow. (C) Localization of PPR $18^{\mathrm{N} 550}$-GFP in tobacco mesophyll cells. Green fluorescence, red fluorescence, and yellow fluorescence (merge) show green fluorescent protein (GFP) fluorescence, MitoTracker stained mitochondria, and localization, respectively. DIC, differential interference contrast. Scale bar, $20 \mu \mathrm{m}$.

\subsection{Embryo and Endosperm Development Are Arrested in ppr18}

To characterize the function of PPR18, we isolated two independent $M$ utator $(M u)$ insertional mutants containing $M u$ insertions at $880 \mathrm{bp}$ and $939 \mathrm{bp}$ downstream from the start codon of PPR18 from the UniformMu population in the inbred W22 genetic background, named ppr18-1 and ppr18-2, respectively [42]. The selfed progeny of both ppr18-1/+ and ppr18-2/+ heterozygotes segregated at a 3:1 ratio of wild-type (WT) and empty pericarp (emp) kernels, suggesting that both mutants are monogenic nuclear recessive mutations and homozygous lethal (Figure 2A and Figure S2A). Co-segregation analysis of a small isolated population with 72 individuals was performed to test the linkage of ppr18-1 by genomic PCR using PPR18-R1 and Mu TIR8 primers [43]. The results showed that all the self-pollinated progenies of ppr18-1/+ plants produced emp kernels, indicating that the $M u$ insertion is tightly linked to the mutation (Figure S3). Crosses between ppr18-1/+ and ppr18-2/+ heterozygotes produced heteroallelic progeny ppr18-1/ppr18-2 with approximately 25\% emp kernels (Figure S2B), confirming that the ppr18 phenotype results from the disruption of GRMZM2G438456. 


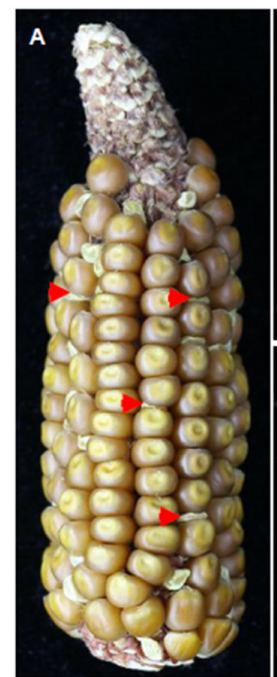

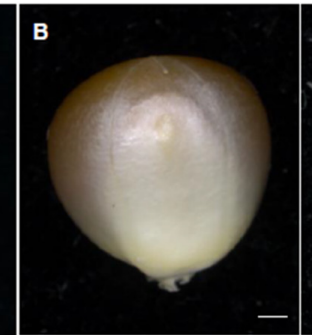

c.

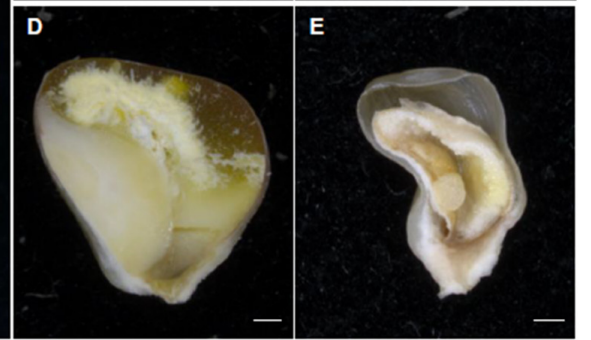

F

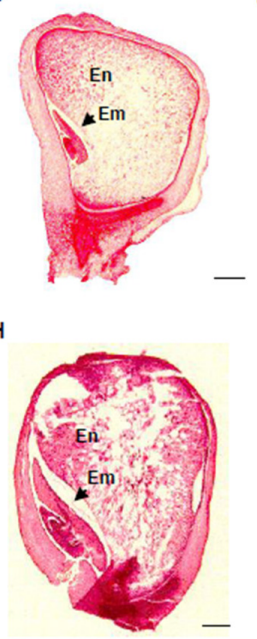

G
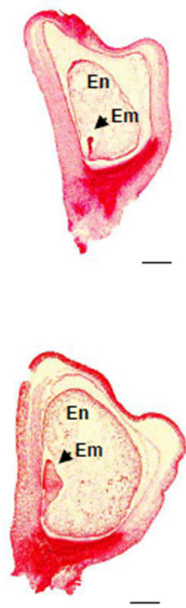

Figure 2. Mutant ppr18-1 kernels abort early in embryogenesis and endosperm development. (A) The mature ear segregates 3:1 for wild-type (WT) and ppr18-1 kernels at 35 days after pollination (DAP). The red arrows indicate the ppr18-1 kernels. (B,C) Mature wild-type (B) and ppr18-1 kernels (C) from (A). (D,E) Dissection of mature wild-type (D) and ppr18-1 kernels (E). (F-I) Paraffin sections of wild-type $(\mathbf{F}, \mathbf{H})$ and ppr18-1 kernels (G,I) at 9 DAP and 14 DAP. Wild-type kernels at 9 DAP (F) and 14 DAP (H); ppr18-1 kernels at 9 DAP (G) and 14 DAP (I). En, endosperm; Em, embryo. Scale bar, $1 \mathrm{~mm}$ in (B-I).

The developing kernels phenotype of WT and ppr18-1 in the same segregating ear are compared in Figure 2B,C. The ppr18-1 mutant kernels are remarkably smaller than the wild type, which exhibited pale, half-translucent, and collapsed appearance at 35 days after pollination (DAP; Figure 2B-E). Compared with the WT siblings in the same segregating ear, the embryo and endosperm development are arrested in the ppr18-1 kernels (Figure 2B-E). To examine the developmental arrest of embryogenesis in ppr18-1, we examined the embryo and endosperm development process between ppr18-1 and WT siblings in a segregating ear by light microscopy. At 9 DAP, the WT embryos reached the coleoptilar stage, whereas the ppr18-1 embryos remained at the pre-embryo stage (Figure 2F,G). At 14 DAP, the WT embryos reached late embryogenesis stage, while the ppr18-1 embryos stayed at the transition stage without any discernable differentiation (Figure 2H,I). These results indicate that the loss of PPR18 severely arrests both embryo and endosperm development.

To assess the impact of the $M u$ insertion on the PPR18 expression, we analyzed the transcript level of PPR18 in two ppr18 alleles by reverse transcription PCR (RT-PCR). Results showed that no transcript of PPR18 was detected in both alleles (Figure S4A), indicating that both alleles are probably null mutations. In wild type, PPR18 transcripts can be detected in all vegetative and reproductive tissues by quantitative real-time PCR (qRT-PCR; Figure S4B). Relative high mRNA expression of PPR18 was in bract and low expression in root, flower and kernel at developmental stages, indicating that PPR18 is a constitutively expressed gene throughout growth and development in maize, rather than a seed specific gene. As the mutants are embryo lethal, impacts on other tissues and during development cannot be determined.

\subsection{Loss of PPR18 Affects Mitochondrial Respiratory Activity}

Previous reports showed the mutation of mitochondrion-localized PPR proteins with arrested seed development often suffers defects in mitochondrial respiration [44-46]. Thus, we investigated whether the loss of PPR18 affects mitochondrial respiratory activity in maize by determining the respiratory activity, as shown by three mitochondrial respiratory rates, including total respiratory $\left(V_{t}\right)$, cytochrome respiratory capacity $\left(V_{c y t}\right)$, and alternative respiratory capacity $\left(V_{\text {alt }}\right)$. The ratio of $\mathrm{V}_{\text {cyt }} / \mathrm{V}_{\mathrm{t}}$ was significantly reduced in the ppr18-1 mutant compared with WT (Table 1), indicating that loss of PPR18 resulted in a severe reduction of the cytochrome pathway and impaired mitochondrial 
respiration. Meanwhile, the ratio of $\mathrm{V}_{\text {alt }} / \mathrm{V}_{\mathrm{t}}$ was markedly increased in ppr18-1 (Table 1), supporting that alternative respiratory pathway was enhanced in the ppr18-1 mutant. Moreover, we detected the expression of alternative oxidase (AOX) protein by Western blot assay using the specific antibody of AOX. Results showed that the abundance of AOX was increased drastically in the ppr18-1 mutant compared to WT (Figure 3C), confirming that mutation of PPR18 enhances the expression of alternative oxidases. The maize genome contains three $A O X$ genes, $A O X 1, A O X 2$, and $A O X 3$. Both RT-PCR and qRT-PCR assays showed that the expression of $A O X 2$ and $A O X 3$ was dramatically increased in the two ppr18 alleles (Figure $3 \mathrm{~A}, \mathrm{~B}$ ), indicating that excessive accumulation of $\mathrm{AOX}$ is caused by upregulation of $A O X 2$ and $A O X 3$ expression in the ppr 18 alleles.

Table 1. Alteration of the respiration rate of the wild type (WT) and ppr18-1 kernels.

\begin{tabular}{cccccc}
\hline & \multicolumn{5}{c}{ Respiration Rate (nmol $\mathbf{O}_{\mathbf{2}} \mathbf{~ m i n}^{\mathbf{- 1}} \mathbf{g}^{\mathbf{- 1}}$ Fresh Weight) } \\
\cline { 2 - 6 } & $\mathbf{V}_{\mathbf{t}}$ & $\mathbf{V}_{\text {alt }}$ & $\mathbf{V}_{\text {cyt }}$ & $\mathbf{V}_{\text {alt }} / \mathbf{V}_{\mathbf{t}} \mathbf{( \% )}$ & $\mathbf{V}_{\mathbf{c y t}} / \mathbf{V}_{\mathbf{t}} \mathbf{( \% )}$ \\
\hline WT & $824.96 \pm 77.23$ & $155.90 \pm 14.10$ & $734.30 \pm 60.97$ & 18.90 & 89.01 \\
\hline ppr18-1 & $175.62 \pm 2.85$ & $136.61 \pm 6.55$ & $39.00 \pm 4.26$ & 77.79 & 22.21 \\
\hline
\end{tabular}

Mitochondrial total respiration rate $\left(\mathrm{V}_{\mathrm{t}}\right)$, the alternative pathway $\left(\mathrm{V}_{\text {alt }}\right)$, and the capacity of the cytochrome pathway $\left(\mathrm{V}_{\text {cyt }}\right)$ were indicated by the oxygen consumption of nmol $\mathrm{O}_{2} \mathrm{~min}^{-1} \mathrm{~g}^{-1}$ fresh weight of the maize kernels at 11 DAP using a Clark-type oxygen electrode. Data are mean values \pm SEs from three independent biological samples.

A

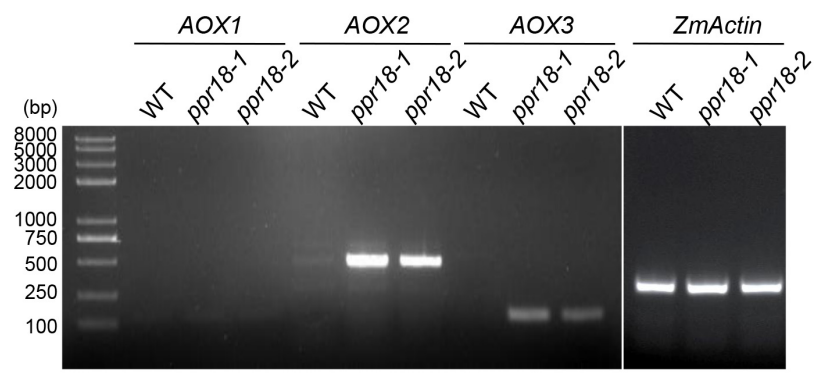

B

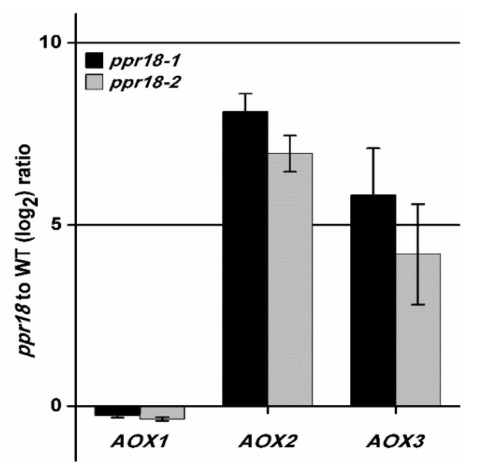

C

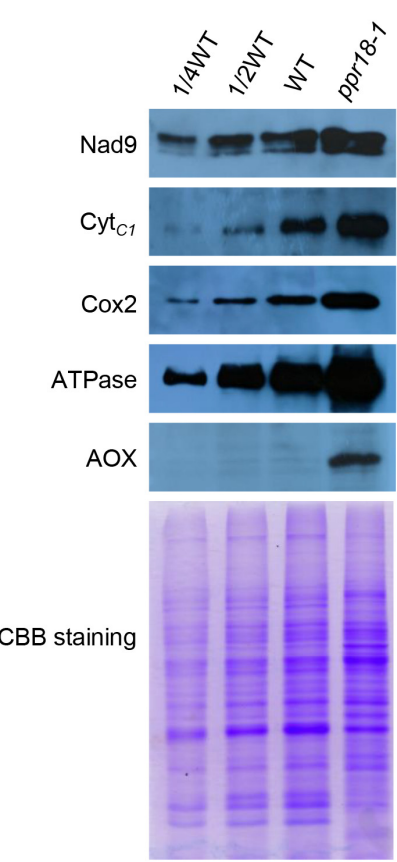

Figure 3. Expression of alternative oxidase $(A O X)$ genes and analysis of protein expression abundance in the PPR18 mutants. (A) The transcript levels of AOX genes in ppr18-1 and ppr18-2 kernels at 12 days after pollination (DAP). The expression levels were normalized to ZmActin (GRMZM2G126010). (B) qRT-PCR analysis of AOX gene expression in ppr18-1 and ppr18-2 kernels at 12 DAP. (C) Western blot analysis with antibodies against $\mathrm{Nad} 9, \mathrm{Cyt}_{\mathrm{C} 1}, \mathrm{Cox} 2$, ATPase a subunit, and AOX. Crude mitochondrial extracts from endosperm and embryo of ppr18-1 and WT immature kernels at 11 DAP. CBB (Coomassie Brilliant Blue) staining demonstrates that equal amounts of mitochondrial proteins were loaded.

\subsection{Loss of PPR18 Affects the Assembly and Activity of Complex I}

The limited cytochrome pathway is closely relevant to the defective transfer electrons from mitochondrial respiratory complexes, complex I to IV [47,48]. To determine the assembly and abundance of mitochondrial respiratory complexes, we performed blue native (BN)-PAGE using crude mitochondria 
from ppr18 alleles and WT maize kernels (Figure 4). As indicated by Coomassie Brilliant Blue (CBB) staining, complex III and V was substantially accumulated, whereas complex I and supercomplex $\mathrm{I}+\mathrm{III}_{2}$ were depleted in both ppr18 alleles compared to WT (Figure 4A), indicating that loss of PPR18 affects the assembly of mitochondrial complex I. Furthermore, we analyzed the NADH dehydrogenase activity of complex I by in-gel NADH activity assay, which showed a consistent result with the CBB staining. As shown in Figure 4B, the dehydrogenase activity of complex I and supercomplex I $+\mathrm{III}_{2}$ were completely deficient in both ppr18 alleles. Besides, we detected the assembly of complex III, IV, and $\mathrm{V}$ by Western blot analysis using the anti-Cyt $\mathrm{C}_{\mathrm{C}}$, anti-Cox2, and anti-ATP synthase $\alpha$-subunit antibody, respectively. Results showed that complex III, IV, and V were increased in the ppr18-1 mutant (Figure 4C-E). Collectively, these results imply that PPR18 is important for the assembly and activity of mitochondrial complex I in maize.

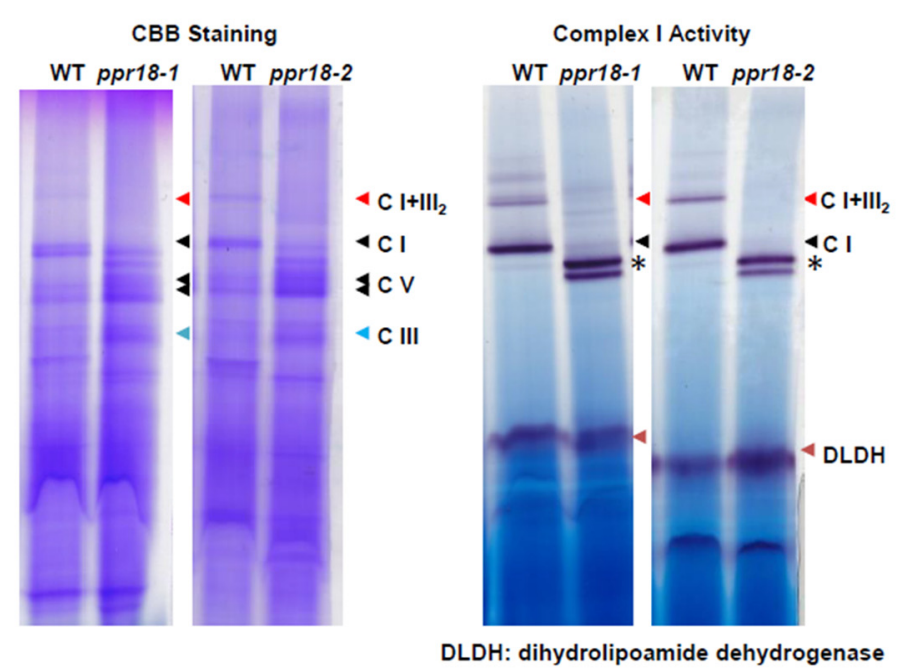

C

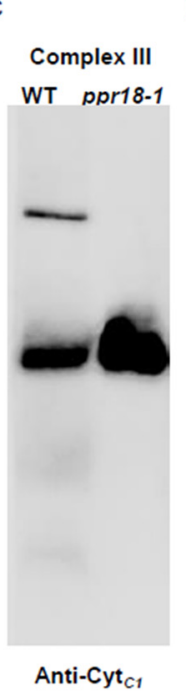

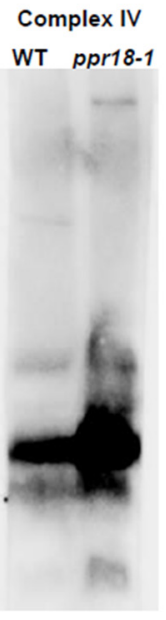

Anti-Cox2 Complex V

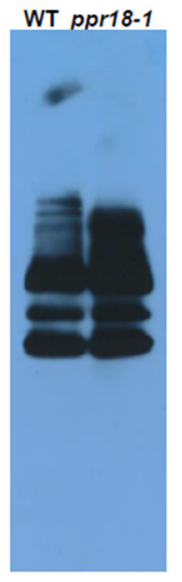

Figure 4. BN-PAGE analysis of mitochondrial complexes in ppr18-1 and ppr18-2 mutants. (A) About $130 \mathrm{mg}$ of mitochondrial protein was loaded to a 3\%-12\% BN-PAGE. Blue native (BN) gels were stained with Coomassie brilliant blue (CBB). The positions of complex I, III, V, and super complex I + $\mathrm{III}_{2}$ are indicated. (B) In-gel NADH dehydrogenase activity of complex I. The activity of dihydrolipoamide dehydrogenase (DLDH) was used as a loading control. Asterisks indicate partially assembled complex I. (C-E) Accumulation of respiratory chain complex III (C), IV (D), and V (E) in ppr18 mutant kernels. The BN gels were probed with antibodies against $\mathrm{Cyt}_{\mathrm{C} 1}, \mathrm{Cox} 2$, and ATPase ( $\alpha$-subunit).

In addition, we determined the abundance of the mitochondrial complex proteins in ppr18-1 and WT maize kernels by Western blot analysis using antibodies against Nad9 (complex I), Cyt ${ }_{C 1}$ (complex III), Cox2 (complex IV), and ATPase (complex V). As shown in Figure 3C, the protein abundance of $\mathrm{Nad} 9, \mathrm{Cyt}_{\mathrm{C} 1}, \mathrm{Cox} 2$, and ATPase was increased in ppr18-1, speculating that the lack of PPR18 may enhance the expression of subunit from complex I, III, IV, and V in a feedback mechanism.

\subsection{PPR18 Is Required for the Splicing of nad4 Intron 1}

Previous study showed that most P-type PPR proteins function on intron splicing, RNA maturation, RNA stabilization or RNA cleavage in organelles [5]. To reveal the molecular function of PPR18, we analyzed the transcript levels of 35 mitochondrion-encoded genes between WT and ppr18 alleles by RT-PCR and qRT-PCR. The results showed that the expression level of most mitochondrion-encoded genes was indistinguishable between the WT and ppr18 alleles, only the expression of nad4 was obviously different between WT and ppr18 alleles (Figure 5 and Figure S5). The mature nad 4 transcript was not detectable in both ppr18 alleles. Instead, a band larger than the mature nad4 transcript was dramatically increased in both ppr18 mutants (Figure 5). The sequencing results of the larger 
fragments showed that these fragments contain unspliced nad4 intron 1 . These results indicate that the loss-of-function in PPR18 abolishes the splicing of nad4 intron 1 in mitochondria.
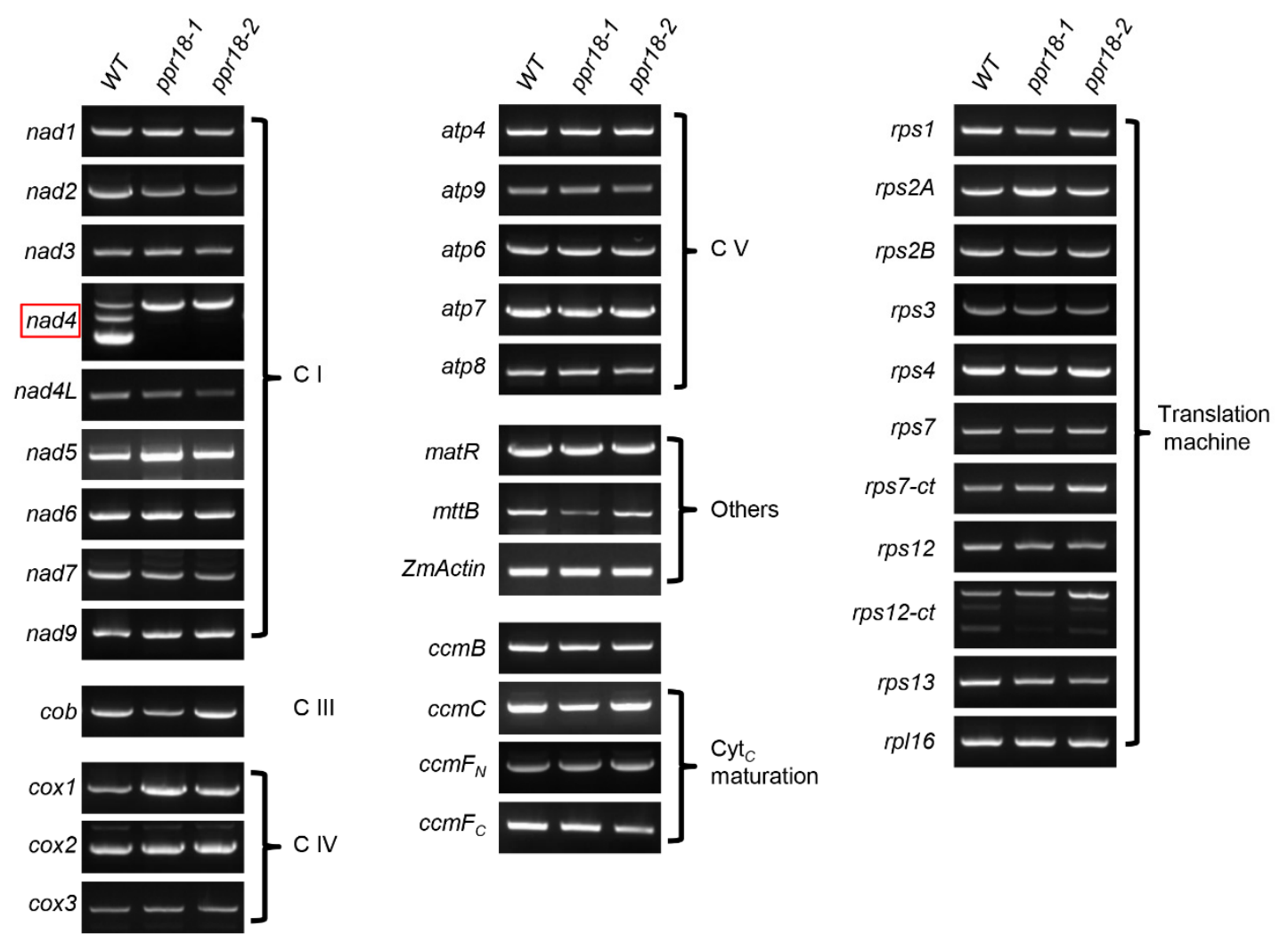

Figure 5. The ppr18 mutants only affect the expression of mitochondrial nad4 mature transcript. The transcript levels of 35 mitochondrion-encoded genes in ppr18-1 and ppr18-2 mutant kernels. The RNA was isolated from the same ear segregating for WT and ppr18 mutants at 13 days after pollination (DAP). The expression levels were normalized to ZmActin (GRMZM2G126010). The absence of nad4 transcripts occurs in both ppr18 alleles (red box indicated). C I: Complex I, C II: Complex II, C III: Complex III, C IV: Complex IV, C V: Complex V.

The nad4 precursor RNA contains three cis-splicing introns (Figure 6A). To confirm the function of PPR18 on the nad4 intron 1 splicing, we amplified fragments containing each of the three introns in the nad4 transcript by RT-PCR using specific primers. As shown in Figure 6B, only the splicing of nad4 intron 1 was impaired in both ppr18 alleles. In addition, we analyzed the splicing efficiency of 22 group II introns in mitochondria by qRT-PCR. Results showed that the splicing efficiency of nad4 intron 1 was dramatically decreased in the ppr18 alleles (Figure 7). These data suggest that PPR18 is indeed required for the splicing of mitochondrial nad4 intron 1. Previous report showed that PPR proteins bind specific RNA via a modular recognition code in which the nucleotide specificity primarily relies on combination at the 5th and 35th amino acid residues of each PPR motif [29-31]. Based on PPR recognition code, potential binding sites of PPR18 in mitochondrial nad4 intron 1 were predicted (Figure 6C). Results showed that the nucleotides of nad4 intron 1 are well aligned to the combinatorial codes. We predicted the secondary structure of nad4 intron 1 and mapped the putative binding site of PPR18 in domain I of nad4 intron 1 (Figure S6). A phylogenetic analysis based on genomic DNAs in the GenBank, the putative binding site of PPR18 in nad4 intron 1 appeared to be highly conserved in both monocots and dicots (Figure S7). 
A

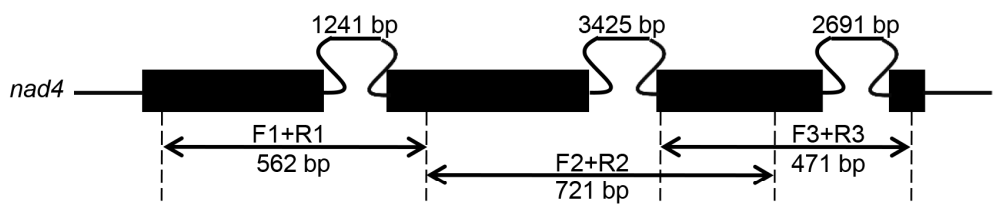

B

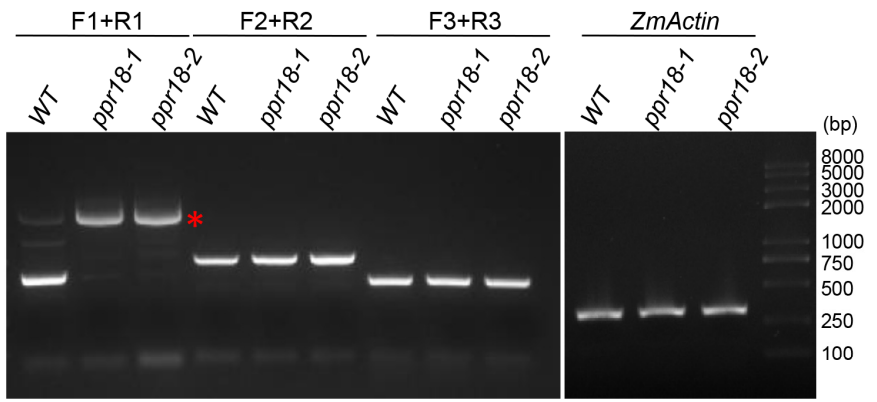

C

\begin{tabular}{|c|c|c|c|c|c|c|c|c|c|c|c|c|c|c|c|c|c|c|}
\hline Repeat & 1 & 2 & 3 & 4 & 5 & 6 & 7 & 8 & 9 & 10 & 11 & 12 & 13 & 14 & 15 & 16 & 17 & 18 \\
\hline $5^{\text {th }} A A$ & V & $\mathrm{N}$ & $\mathrm{T}$ & C & $\mathrm{N}$ & $\mathrm{N}$ & $\mathrm{N}$ & $\mathrm{N}$ & C & $\mathrm{N}$ & $\mathrm{N}$ & $\mathrm{N}$ & $\mathrm{N}$ & $\mathrm{N}$ & $\mathrm{N}$ & $\mathrm{N}$ & $\mathrm{R}$ & G \\
\hline $35^{\text {th }} \mathrm{AA}$ & A & D & K & D & $\mathrm{N}$ & D & D & D & D & D & D & D & $\mathrm{N}$ & D & $\mathrm{T}$ & D & $s$ & $\mathrm{E}$ \\
\hline $\begin{array}{c}\text { Base } \\
\text { preference }\end{array}$ & $?$ & $U>C$ & ? & G & $\mathrm{C}>\mathrm{U}$ & $U>C$ & $U>C$ & $U>C$ & G & $U>C$ & $U>C$ & $U>C$ & $\mathrm{C}>\mathrm{U}$ & $U>C$ & $\mathrm{C}>\mathrm{U}$ & $U>C$ & $?$ & $?$ \\
\hline $\begin{array}{c}\text { nad4 } \\
\text { intron1 }\end{array}$ & G & C & A & G & G & U & U & A & G & U & U & C & C & U & C & U & G & U \\
\hline
\end{tabular}

Figure 6. The ppr18 mutants are impaired in the splicing of nad4 intron 1. (A) Gene structure diagram of the maize nad4 gene. Exons are shown as filled black boxes. All the three introns of nad4 are cis-introns. The primers and expected amplification products using are indicated. F: Forward primer, R: Reverse primer. (B) RT-PCR analysis of the intron splicing of nad4 introns using primers as indicated in (A). Asterisk indicates the unspliced PCR products of nad4 intron 1. (C) Binding predictions for the PPR18 proteins on the respective targets nad4 intron 1 referred to Barkan et al., 2012; Yin et al., 2013; and Gully et al., 2015. The amino acid (AA) residues at position 5th and 35th in PPR motifs 1-18 are indicated. Nucleotides matching the amino acid combination are indicated in red. "?" indicates an unidentified nucleotide.

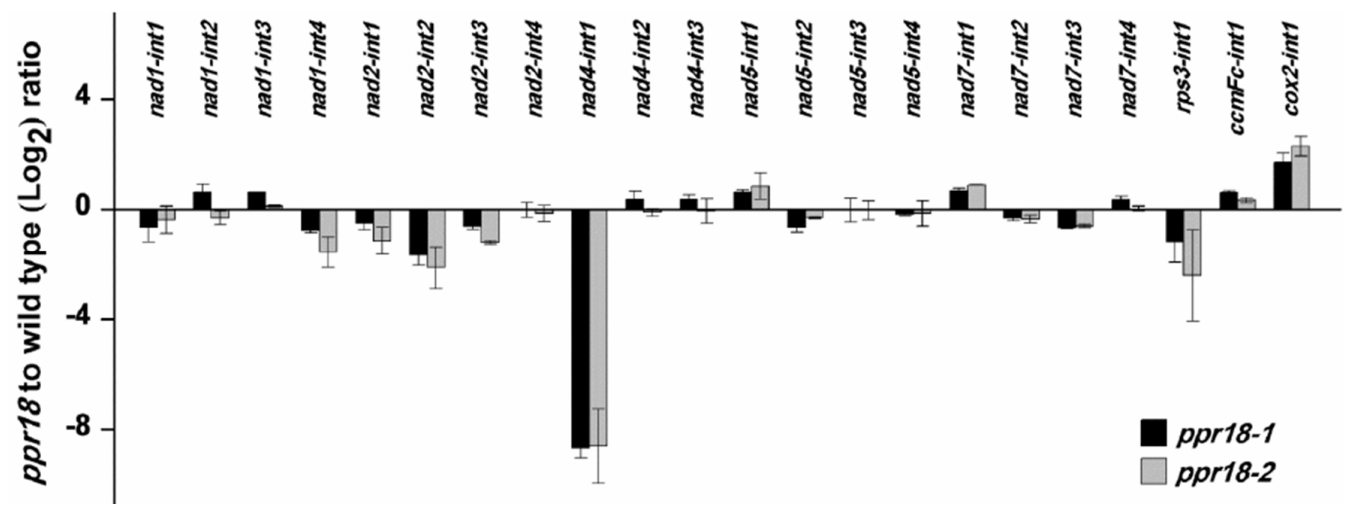

Figure 7. Splicing efficiency of mitochondrial introns in ppr18 mutants. qRT-PCR analysis of the splicing efficiency of all 22 group II introns of maize mitochondrial genes in ppr18 mutants. The ratio of spliced to unspliced fragments was used to measure splicing efficiency. Data are means $( \pm \mathrm{SE})$ of three biological replicates. 
2.6. PPR18 Does Not Show a Direct Interaction with DEK35, EMP8, and EMP602 in Yeast Two-Hybrid Assays

Previous studies reported that three PPR proteins DEK35, EMP8, and EMP602 are involved in the splicing of mitochondrial nad4 intron 1 in maize $[46,49,50]$. In this study, PPR18 is also required for the splicing of nad4 intron 1. To determine whether PPR18 interacts with DEK35, EMP8, and EMP602, we performed a yeast two-hybrid assay. Results showed that PPR18 has no directly physical interaction with these proteins (Figure S8).

\section{Discussion}

\subsection{A Role of PPR18 on nad4 Intron 1 Splicing and the Assembly of Complex I}

The maize mitochondria contain a total of 22 group II introns in 8 genes (nad1, nad2, nad4, nad5, $n a d 7, c c m F c$, cox2, and $r p s 3$ ) [4]. Some PPR proteins have been reported to be responsible for the splicing of group II introns in maize mitochondria (Table 2). Loss-of-function of these PPR proteins usually results in empty pericarp (emp) or defective kernel (dek) phenotype in maize. For example, disruption of Dek2 and Dek37 causes small kernels and delayed development, leading to a dek phenotype of maize [35,38]. The mutation of Emp16 and Emp10 severely arrests seed development, resulting in embryo lethality and an emp phenotype of maize [25,39]. Similarly, the loss of PPR18 function severely arrests the embryo and endosperm development (Figure 2), leading to the emp phenotype, suggesting that PPR18 is crucial for maize kernel development.

Table 2. List of mitochondrion-localized PPR proteins are involved in intron splicing of mitochondrial genes in maize.

\begin{tabular}{ccc}
\hline Protein & Target Transcript & Reference \\
\hline EMP16 & nad2-int4 & (Xiu et al., 2016) \\
EMP10 & nad2-int1 & (Cai et al., 2017) \\
DEK35 & nad4-int1 & (Chen et al., 2017) \\
DEK2 & nad1-int1 & (Qi et al., 2017) \\
EMP11 & nad1-int1, 2, 3,4 & (Ren et al., 2017) \\
DEK37 & nad2-int1 & (Dai et al., 2018) \\
EMP8 & nad1-int4, nad2-int1, nad4-int1 & (Sun et al., 2018) \\
EMP12 & nad2-int1, 2, 4 & (Sun et al., 2019) \\
DEK41/DEK43 & nad4-int3 & (Ren et al., 2019; Zhu et al., 2019) \\
PPR-SMR1 & nad1-int1, 2, 3, 4, nad2-int1, 2, 3, 4, nad4-int1, 2, 3, & (Chen et al., 2019) \\
EMP602 & nad5-int1, 3, 4, nad7-int2, rps3-int1 & (Ren et al., 2019) \\
PPR20 & nad4-int1, 3 & (Yang et al., 2019) \\
PPR18 & nad2-int3 & This study \\
\hline
\end{tabular}

As shown in Table 2, these PPR proteins (EMP8, EMP10, EMP11, EMP12, EMP16, EMP602, DEK2, DEK35, DEK37, DEK41, DEK43, PPR-SMR1, and PPR20) are reported to participate in the splicing of nad1, nad2, nad4, nad5, nad7, and rps3 introns. These nad genes encode the core subunits of mitochondrial complex I and lack of these Nad proteins causes the disassembly and reduced activity of complex I in maize [51]. For example, EMP11 is responsible for the intron splicing of nad1 and the dysfunction of Emp11 affects the assembly and stability of mitochondrial complex I [34]. EMP12 and PPR20 are essential for the splicing of nad2 introns. The mutation of EMP12 and PPR20 results in disassembly of mitochondrial complex I and a significant reduction in the dehydrogenase activity [36,37]. In this study, loss of PPR18 impaired the cis-splicing of nad4 intron 1 and the accumulation of mature nad4 transcript (Figure 5), leading to severely defective assembly and activity of mitochondrial complex I in the ppr18 mutants, suggesting the importance of PPR18 in the intron splicing of nad 4 transcript and the assembly and activity of mitochondrial complex I. The splicing of nad4 intron 1 was dramatically reduced in dek35, and completely abolished in emp8, emp602, and ppr18 [46,49,50], causing a deficiency 
in the mature nad4 transcript and severely arrested embryo and endosperm development in maize. Together, these results indicate that expression of nad4 is essential to the mitochondrial function and kernel development in maize. A co-evolution between the mitochondrial nad4 intron 1 and the nuclear PPR18 genes are implicated as indicated by the highly conserved sequences between PPR18 and its putative binding site in nad4 intron 1 in both monocots and dicots (Figures S1 and S7).

In Figure 4, the in-gel NADH activity assay showed that two bands with a smaller size than mature complex I were produced in ppr18 alleles, which are probably partially assembled complex I. Additionally, the two smaller size complexes had the dehydrogenase activity (Figure 4B), indicating the two partially assembled complex I are stable intermediate of the mitochondrial complex I assembly pathway in maize. Similar cases were also found in the dek35, emp602, dek41, and dek43 mutants, which are defective in the splicing of nad4 introns and [49,50,52,53], supporting that Nad4 is assembled into the complex I at a late stage. As reported in Arabidopsis, Nad4 is located in the $\mathrm{P}_{\mathrm{D}}$ module of the membrane arm of mitochondrial complex I, which is associated with assembled intermediate to form the mature complex I [51], indicating that Nad4 plays a crucial role during the last phase of the complex I assembly process both in monocots and dicots.

Previous reports showed that impairments in the electron transfer chain (ETC) can enhance AOX pathway in mitochondria [54-56]. In the ppr18 alleles, the ratio of $\mathrm{V}_{\mathrm{alt}} / \mathrm{V}_{\mathrm{t}}$, the abundance of AOX protein, and the expression of $A O X 2$ and $A O X 3$ transcripts were notably increased (Figure 3 ), indicating that AOX pathway is significantly enhanced in ppr18. A retrograde signalling pathway is strongly implicated as the AOXs are nucleus-encoded proteins.

\subsection{Multiple Splicing Factors Participate in the Splicing of nad4 Intron 1}

The defective splicing of nad4 intron 1 was firstly reported in Nicotiana sylvestris nms1 mutant [57]. In maize, defects of splicing of nad4 intron 1 have been found in some ppr mutants, e.g., dek35, emp8, and emp602 [46,49,50]. Our data show that PPR18 also specifically functions on the splicing of nad4 intron 1 in maize. These splicing factors share common intron target with PPR18, implying that splicing of a single intron requires multiple splicing factors. Based on the yeast two-hybrid analyses, however, PPR18 does not directly interact with DEK35, EMP8, and EMP602 (Figure S8).

It is possible that these PPR proteins function independently by binding to the specific sequences of nad 4 intron 1 to maintain a splicing-competent structure, and these proteins do not have protein interactions with each other. Proteins could promote group II intron folding to form the native structure [58]. PPR proteins are RNA binding proteins that could guide intron folding by sequence-specific interactions [59]. PPR18 may play a role in folding of nad4 intron 1 to participate in the intron splicing of nad4 transcript.

As the intron splicing mechanism in mitochondria is not clear yet, all co-factors may have not been identified. The possibility of a ribonucleoprotein complex similar to the nuclear spliceosome exists for some introns. Thus, it is possible that PPR18 may interact with other splicing co-factors. The tested PPR proteins may interact with some key splicing factors exist in splicing complexes to mediate splicing of nad4 intron 1. For example, PPR-SMR1 interacts with Zm-mCSF1 to participate in the splicing of several mitochondrial group II introns, speculating that PPR-SMR1 and Zm-mCSF1 might be the core splicing factors to mediate multiply group II introns splicing [60]. Further studies are necessary to unravel the splicing mechanism of plant organellar group II introns.

\section{Materials and Methods}

\subsection{Plant Materials}

The ppr18 alleles (UFMu-06715 and UFMu-11033) were obtained from the Maize Genetics Cooperation Stock Center (Urbana, IL, USA). For developmental analyses and population generation, the maize plants were cultivated in the experimental filed of Shandong University in Qingdao. Tobacco 
(Nicotiana tabacum) was grown in climate chambers at $25{ }^{\circ} \mathrm{C} / 22{ }^{\circ} \mathrm{C}$ day/night on a $12 \mathrm{~h} \mathrm{light} / 12 \mathrm{~h}$ dark regime.

\subsection{Subcellular Localization}

To express PPR18 N550-GFP fusion proteins, the amplified PPR18 N-terminal coding sequence (1650 bp) was cloned into binary vector pGWB5 driven by the 355 promoter. Agrobacterium tumefaciens strain (EHA105) harboring this construct was infiltrated into tobacco (Nicotiana tabacum) leaf epidermis with a syringe, as previously described [61]. After incubation at $24{ }^{\circ} \mathrm{C}$ for $24-30 \mathrm{~h}$, the GFP signals were observed and imaged using ZEISS LSM 880 confocal microscope (Carl-Zeiss, Jena, Germany). MitoTracker Red (ThermoFisher Scientific, Waltham, MA, USA) was used as the mitochondrion marker with a working concentration of $100 \mathrm{nM}$.

\subsection{Light Microscopy of Cytological Sections}

ppr18-1/+ heterozygotes were identified by PCR with Mu primer TIR8 and gene primer PPR18-R1. Immature WT and ppr18-1 kernels were harvested from the self-pollinated heterozygous segregating ear at 9 and 14 days after pollination (DAP). The fixed material and sections were performed as described previously [62]. Paraffin sections were stained with 1\% Johansen's Safranin O and imaged with a stereo microscope (Carl-Zeiss, Jena, Germany).

\subsection{RNA Extraction, RT-PCR, and $q R T-P C R$}

Total RNA was extracted from fresh kernels by removing the pericarp using TRIzol reagent (ThermoFisher Scientific, Waltham, MA, USA). After DNaseI digestion (NEB) to eliminate DNA contamination, reverse transcription was conducted with random primers according to the manufacturer's instructions (TransGen Company, Beijing, China). Quantitative real time PCR (qRT-PCR) was performed with using LightCycler 96 (Roche, Basel, Switzerland) with three biological replicates. The maize actin gene ZmActin (GRMZM2G126010) was used as the reference gene. For functional analysis of PPR18, RT-PCR and qRT-PCR were performed with primers as previously described [45,49].

\subsection{Measurements of Respiration Rate}

The respiration rates were determined according to the previous report with some modifications [63]. The respiratory activities were measured in a reaction medium ( $50 \mathrm{mM}$ phosphate buffer, $\mathrm{pH} 6.8$ ) at $25{ }^{\circ} \mathrm{C}$ in the dark using a Chlorolab II liquid oxygen electrode (Hansatech, King's Lynn, UK, http://hansatech-instruments.com). The alternative pathway capacity $\left(\mathrm{V}_{\text {alt }}\right)$ and cytochrome pathway capacity $\left(\mathrm{V}_{\text {cyt }}\right)$ are defined as $\mathrm{O}_{2}$ uptake rate in the presence of $2 \mathrm{mM}$ potassium cyanide $(\mathrm{KCN}$; Sigma-Aldrich, St. Louis, MO, USA, catalog number: 207810) and $2 \mathrm{mM}$ salicylhydroxamic acid (SHAM; Sigma-Aldrich, St. Louis, MO, USA, catalog number: S607), respectively. All the respiration rates were indicated by the oxygen consumption of $\mathrm{nmol} \mathrm{O}_{2} \mathrm{~min}^{-1} \mathrm{~g}^{-1}$ fresh weight of the maize kernels.

\subsection{Blue Native (BN)-PAGE and Complex I Activity Assay}

Crude mitochondrial proteins were extracted from immature maize kernels with the pericarp removed at 11 DAP. Blue native (BN)-PAGE and measurement of NADH dehydrogenase activity were performed as previously described [64]. Of maize mitochondrial proteins $130 \mu \mathrm{g}$ was separated by $3 \%-12.5 \%$ gradient gel (ThermoFisher Scientific, Waltham, MA, USA). The gel strips were stained by Coomassie Blue R-250 and assayed for complex I activity in nitroblue tetrazolium (NBT)-NADH buffer ( $25 \mathrm{mg}$ of NBT, $100 \mu \mathrm{L}$ of NADH $\left(10 \mathrm{mg} \mathrm{mL}^{-1}\right)$, and $10 \mathrm{~mL}$ of $5 \mathrm{mM}$ Tris-HCl, pH 7.4). The gel strips were transferred to the nitrocellulose membrane and Western blotting with specific antibodies

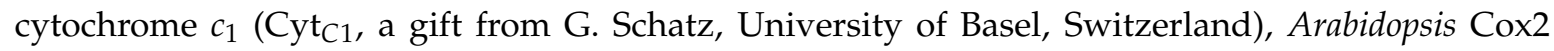
(Agrisera, Vännäs, Sweden, http://www.agrisera.com), and ATPase (ATPase $\alpha$-subunit, MBL Beijing Biotech, China) for detection of complex III, VI, and V, respectively [64]. 


\subsection{Immunoblot Analysis}

Proteins extracted from immature maize kernels were determined by $12.5 \%$ SDS-PAGE and transferred to the Polyvinylidene Fluoride (PVDF, GE healthcare, Freiburg im Breisgau, Germany) membrane and Western blotting using antiserum against $\mathrm{Cyt}_{\mathrm{C} 1}$ (1:5000), Cox2 (1:5000), ATPase $(1: 10,000), \operatorname{AOX}(1: 10,000)[25]$, and wheat $\operatorname{Nad} 9$ (1:3000) [65], as previously described [44]. The membrane was treated with ECL reagents (Pierce, ThermoFisher Scientific, Waltham, MA, USA). Signals were visualized on X-ray films (Kodak, Tokyo, Japan) and imaged using a Tanon-5200 system (Tanon, Shanghai, China).

\subsection{Yeast Two-Hybrid Analysis}

Yeast two-hybrid analysis was performed according to the manual of Matchmaker ${ }^{\mathrm{TM}}$ Gold Yeast Two-Hybrid System (Clontech, Mountain View, CA, USA). The coding sequence (CDS) without signal peptide sequences of PPR18, DEK35, EMP8, and EMP602 were cloned pGADT7 vector and pGBKT7 vector, respectively. The primer sequences are listed in Table S1. Combinations of plasmids were co-transformed into the yeast strain Y2H Gold (Clontech, Mountain View, CA, USA) and placed on SD/-Leu/-Trp (Minimal Media Double Dropouts, DDO) mediums and growth of diploid yeast colonies on SD/-Ade/-His/-Leu/-Trp (Minimal Media Quadruple Dropouts, QDO) mediums for 4 days at $30^{\circ} \mathrm{C}$ to reveal protein-protein interactions.

\subsection{Prediction of PPR18 Binding Site}

PPR motif prediction alignment analysis of PPR18 protein was used by algorithm TPRpred (http://tprpred.tebingen.mpg.de/tprpred). The alignment of PPR18 to its nad4 intron 1 binding site was generated as follows the PPR codes [29-31]. The recognition nucleotides for the PPR18 protein were predicted by the arrangements of the amino acids at position 5th and 35th of each PPR repeat from PPR18. The respective recognition nucleotides were listed and aligned with nad4 intron 1 to find the best matched nucleotide sites as potential binding sites of PPR18 in mitochondrial nad4 intron 1.

\subsection{Phylogenetic Analysis}

The full-length amino acid sequences of PPR18, the putative binding site of PPR18 in nad4 intron 1 , and their orthologs in plant species were downloaded from NCBI database (https://blast.ncbi.nlm. nih.gov). The phylogenetic tree was constructed using MEGA7 software by the maximum likelihood method [66].

\section{Conclusions}

In this study, we characterized a maize seed mutant ppr18, which exhibits an arrested embryo and endosperm development phenotype. Through a molecular characterization of the PPR18 gene, we elucidated its function in the cis-splicing of nad 4 intron 1 in mitochondria and seed development in maize. The lack of splicing of nad4 intron 1 results in the absence of nad4 transcript, leading to severely reduced assembly and activity of mitochondrial complex I. The profiles of complex I assembly, activity, and component accumulation in the ppr18 mutants shed lights to the assembly process of complex I in maize. Despite PPR proteins have been reported in intron splicing, our study provides additional information on a new PPR protein in intron splicing, complex I assembly, and its essential role in maize seed development.

Supplementary Materials: Supplementary materials can be found at http:/www.mdpi.com/1422-0067/21/11/ 4047/s1, Figure S1: Phylogenetic analysis of PPR18 homologs, Figure S2: Phenotypes of the ppr18-2 mutant and the ear of ppr18-1 × ppr18-2, Figure S3: The linkage analysis of the $M u$ insertion in PPR18-1 and the phenotype in the selfed progeny, Figure S4: Expression of PPR18, Figure S5: Transcript levels of the 35 mitochondrial genes in ppr18 alleles in developing kernels, Figure S6: The predicted secondary structure of maize nad4 intron 1 and the location of the putative binding site, Figure S7: Alignment of the putative binding site of PPR18 in nad4 intron 1 in 
different plant species, Figure S8: Interaction assay of PPR18 and the related splicing factors, Table S1: Primers used in this study.

Author Contributions: R.L. and B.-C.T. conceived and designed the experiments. R.L., S.-K.C., A.S., F.S., and X.W. performed the experiments. R.L., S.-K.C., and B.-C.T. analyzed data and wrote the manuscript. C.X. contributed to reagents/materials/analysis tools. All authors have read and agreed to the published version of the manuscript.

Funding: This work was supported by a grant from the National Natural Science Foundation of China (31630053, 91735301 to B.-C.T., and 31900264 to R.L.) and a grant from the China Postdoctoral Science Foundation (2017M612262).

Acknowledgments: We appreciate Tsuyoshi Nakagawa (Shimane University, Japan) for providing the pGWB vectors.

Conflicts of Interest: The authors declare no conflict of interest.

\section{References}

1. Timmis, J.N.; Ayliffe, M.A.; Huang, C.Y.; Martin, W. Endosymbiotic gene transfer: Organelle genomes forge eukaryotic chromosomes. Nat. Rev. Genet. 2004, 5, 123-135. [CrossRef] [PubMed]

2. Unseld, M.; Marienfeld, J.R.; Brandt, P.; Brennicke, A. The mitochondrial genome of Arabidopsis thaliana contains 57 genes in 366,924 nucleotides. Nat. Genet. 1997, 15, 57-61. [CrossRef] [PubMed]

3. Notsu, Y.; Masood, S.; Nishikawa, T.; Kubo, N.; Akiduki, G.; Nakazono, M.; Hirai, A.; Kadowaki, K. The complete sequence of the rice (Oryza sativa L.) mitochondrial genome: Frequent DNA sequence acquisition and loss during the evolution of flowering plants. Mol. Genet. Genomics 2002, 268, 434-445. [CrossRef] [PubMed]

4. Clifton, S.W.; Minx, P.; Fauron, C.M.; Gibson, M.; Allen, J.O.; Sun, H.; Thompson, M.; Barbazuk, W.B.; Kanuganti, S.; Tayloe, C.; et al. Sequence and comparative analysis of the maize NB mitochondrial genome. Plant Physiol. 2004, 136, 3486-3503. [CrossRef]

5. Barkan, A.; Small, I. Pentatricopeptide repeat proteins in plants. Annu. Rev. Plant Biol. 2014, 65, 415-442. [CrossRef]

6. Delannoy, E.; Stanley, W.A.; Bond, C.S.; Small, I.D. Pentatricopeptide repeat (PPR) proteins as sequencespecificity factors in post-transcriptional processes in organelles. Biochem. Soc. Trans. 2007, 35, 1643-1647. [CrossRef]

7. Kramer, M.C.; Anderson, S.J.; Gregory, B.D. The nucleotides they are a-changin': Function of RNA binding proteins in post-transcriptional messenger RNA editing and modification in Arabidopsis. Curr. Opin. Plant Biol. 2018, 45, 88-95. [CrossRef]

8. Bonen, L. Cis- and trans-splicing of group II introns in plant mitochondria. Mitochondrion 2008, 8, $26-34$. [CrossRef]

9. Lambowitz, A.M.; Zimmerly, S. Mobile group II introns. Annu. Rev. Genet. 2004, 38, 1-35. [CrossRef]

10. Cech, T.R. Self-splicing of group I introns. Annu. Rev. Biochem. 1990, 59, 543-568. [CrossRef]

11. Zoschke, R.; Nakamura, M.; Liere, K.; Sugiura, M.; Borner, T.; Schmitz-Linneweber, C. An organellar maturase associates with multiple group II introns. Proc. Natl. Acad. Sci. USA 2010, 107, 3245-3250. [CrossRef] [PubMed]

12. Vogel, J.; Börner, T.; Hess, W.R. Comparative analysis of splicing of the complete set of chloroplast group II introns in three higher plant mutants. Nucleic Acids Res. 1999, 27, 3866-3874. [CrossRef] [PubMed]

13. Cohen, S.; Zmudjak, M.; Colas des Francs-Small, C.; Malik, S.; Shaya, F.; Keren, I.; Belausov, E.; Many, Y.; Brown, G.G.; Small, I.; et al. nMAT4, a maturase factor required for nad1 pre-mRNA processing and maturation, is essential for holocomplex I biogenesis in Arabidopsis mitochondria. Plant J. 2014, 78, 253-268. [CrossRef] [PubMed]

14. Keren, I.; Tal, L.; des Francs-Small, C.C.; Araujo, W.L.; Shevtsov, S.; Shaya, F.; Fernie, A.R.; Small, I.; Ostersetzer-Biran, O. nMAT1, a nuclear-encoded maturase involved in the trans-splicing of nad1 intron 1, is essential for mitochondrial complex I assembly and function. Plant J. 2012, 71, 413-426. [CrossRef]

15. Keren, I.; Bezawork-Geleta, A.; Kolton, M.; Maayan, I.; Belausov, E.; Levy, M.; Mett, A.; Gidoni, D.; Shaya, F.; Ostersetzer-Biran, O. AtnMat2, a nuclear-encoded maturase required for splicing of group-II introns in Arabidopsis mitochondria. RNA 2009, 15, 2299-2311. [CrossRef]

16. Till, B.; Schmitz-Linneweber, C.; Williams-Carrier, R.; Barkan, A. CRS1 is a novel group II intron splicing factor that was derived from a domain of ancient origin. RNA 2001, 7, 1227-1228. [CrossRef] 
17. Zmudjak, M.; Colas des Francs-Small, C.; Keren, I.; Shaya, F.; Belausov, E.; Small, I.; Ostersetzer-Biran, O. mCSF1, a nucleus-encoded CRM protein required for the processing of many mitochondrial introns, is involved in the biogenesis of respiratory complexes I and IV in Arabidopsis. New Phytol. 2013, 199, 379-394. [CrossRef]

18. Asakura, Y.; Galarneau, E.; Watkins, K.P.; Barkan, A.; van Wijk, K.J. Chloroplast RH3 DEAD box RNA helicases in maize and Arabidopsis function in splicing of specific group II introns and affect chloroplast ribosome biogenesis. Plant Physiol. 2012, 159, 961-974. [CrossRef]

19. Bobik, K.; McCray, T.N.; Ernest, B.; Fernandez, J.C.; Howell, K.A.; Lane, T.; Staton, M.; Burch-Smith, T.M. The chloroplast RNA helicase ISE2 is required for multiple chloroplast RNA processing steps in Arabidopsis thaliana. Plant J. 2017, 91, 114-131. [CrossRef]

20. Hammani, K.; Barkan, A. An mTERF domain protein functions in group II intron splicing in maize chloroplasts. Nucleic Acids Res. 2014, 42, 5033-5042. [CrossRef]

21. Hsu, Y.W.; Wang, H.J.; Hsieh, M.H.; Hsieh, H.L.; Jauh, G.Y. Arabidopsis mTERF15 is required for mitochondrial nad2 intron 3 splicing and functional complex I activity. PLoS ONE 2014, 9, e112360. [CrossRef] [PubMed]

22. Colas des Francs-Small, C.; Kroeger, T.; Zmudjak, M.; Ostersetzer-Biran, O.; Rahimi, N.; Small, I.; Barkan, A. A PORR domain protein required for $r p l 2$ and $c c m F_{C}$ intron splicing and for the biogenesis of $c$-type cytochromes in Arabidopsis mitochondria. Plant J. 2012, 69, 996-1005. [CrossRef] [PubMed]

23. Kroeger, T.S.; Watkins, K.P.; Friso, G.; van Wijk, K.J.; Barkan, A. A plant-specific RNA-binding domain revealed through analysis of chloroplast group II intron splicing. Proc. Natl. Acad. Sci. USA 2009, 106, 4537-4542. [CrossRef] [PubMed]

24. Kuhn, K.; Carrie, C.; Giraud, E.; Wang, Y.; Meyer, E.H.; Narsai, R.; des Francs-Small, C.C.; Zhang, B.; Murcha, M.W.; Whelan, J. The RCC1 family protein RUG3 is required for splicing of nad2 and complex I biogenesis in mitochondria of Arabidopsis thaliana. Plant J. 2011, 67, 1067-1080. [CrossRef] [PubMed]

25. Xiu, Z.; Sun, F.; Shen, Y.; Zhang, X.; Jiang, R.; Bonnard, G.; Zhang, J.; Tan, B.C. EMPTY PERICARP16 is required for mitochondrial nad2 intron 4 cis-splicing, complex I assembly and seed development in maize. Plant J. 2016, 85, 507-519. [CrossRef]

26. Schmitz-Linneweber, C.; Williams-Carrier, R.E.; Williams-Voelker, P.M.; Kroeger, T.S.; Vichas, A.; Barkan, A. A pentatricopeptide repeat protein facilitates the trans-splicing of the maize chloroplast $r p s 12$ pre-mRNA. Plant Cell 2006, 18, 2650-2663. [CrossRef]

27. Lurin, C.; Andres, C.; Aubourg, S.; Bellaoui, M.; Bitton, F.; Bruyere, C.; Caboche, M.; Debast, C.; Gualberto, J.; Hoffmann, B.; et al. Genome-wide analysis of Arabidopsis pentatricopeptide repeat proteins reveals their essential role in organelle biogenesis. Plant Cell 2004, 16, 2089-2103. [CrossRef]

28. Fujii, S.; Small, I. The evolution of RNA editing and pentatricopeptide repeat genes. New Phytol. 2011, 191, 37-47. [CrossRef]

29. Barkan, A.; Rojas, M.; Fujii, S.; Yap, A.; Chong, Y.S.; Bond, C.S.; Small, I. A combinatorial amino acid code for RNA recognition by pentatricopeptide repeat proteins. PLoS Genet. 2012, 8, e1002910. [CrossRef]

30. Gully, B.S.; Cowieson, N.; Stanley, W.A.; Shearston, K.; Small, I.D.; Barkan, A.; Bond, C.S. The solution structure of the pentatricopeptide repeat protein PPR10 upon binding atpH RNA. Nucleic Acids Res. 2015, 43, 1918-1926. [CrossRef]

31. Yin, P.; Li, Q.; Yan, C.; Liu, Y.; Liu, J.; Yu, F.; Wang, Z.; Long, J.; He, J.; Wang, H.W.; et al. Structural basis for the modular recognition of single-stranded RNA by PPR proteins. Nature 2013, 504, 168-171. [CrossRef] [PubMed]

32. Burger, G.; Gray, M.W.; Lang, B.F. Mitochondrial genomes: Anything goes. Trends Genet. 2003, 19, 709-716. [CrossRef] [PubMed]

33. Berrisford, J.M.; Sazanov, L.A. Structural basis for the mechanism of respiratory complex I. J. Biol. Chem. 2009, 284, 29773-29783. [CrossRef] [PubMed]

34. Ren, X.; Pan, Z.; Zhao, H.; Zhao, J.; Cai, M.; Li, J.; Zhang, Z.; Qiu, F. EMPTY PERICARP11 serves as a factor for splicing of mitochondrial nad1 intron and is required to ensure proper seed development in maize. J. Exp. Bot. 2017, 68, 4571-4581. [CrossRef]

35. Qi, W.; Yang, Y.; Feng, X.; Zhang, M.; Song, R. Mitochondrial function and maize kernel development requires Dek2, a pentatricopeptide repeat protein involved in nad1 mRNA splicing. Genetics 2017, 205, 239-249. [CrossRef] 
36. Sun, F.; Xiu, Z.; Jiang, R.; Liu, Y.; Zhang, X.; Yang, Y.Z.; Li, X.; Zhang, X.; Wang, Y.; Tan, B.C. The mitochondrial pentatricopeptide repeat protein EMP12 is involved in the splicing of three nad 2 introns and seed development in maize. J. Exp. Bot. 2019, 70, 963-972. [CrossRef]

37. Yang, Y.Z.; Ding, S.; Wang, Y.; Wang, H.C.; Liu, X.Y.; Sun, F.; Xu, C.; Liu, B.; Tan, B.C. PPR20 is required for the cis-splicing of mitochondrial nad2 intron 3 and seed development in maize. Plant Cell Physiol. 2020, 61, 370-380. [CrossRef]

38. Dai, D.; Luan, S.; Chen, X.; Wang, Q.; Feng, Y.; Zhu, C.; Qi, W.; Song, R. Maize Dek37 encodes a P-type PPR protein that affects cis-splicing of mitochondrial nad2 intron 1 and seed development. Genetics 2018, 208, 1069-1082. [CrossRef]

39. Cai, M.; Li, S.; Sun, F.; Sun, Q.; Zhao, H.; Ren, X.; Zhao, Y.; Tan, B.C.; Zhang, Z.; Qiu, F. Emp10 encodes a mitochondrial PPR protein that affects the cis-splicing of nad2 intron 1 and seed development in maize. Plant J. 2017, 91, 132-144. [CrossRef]

40. Ding, Y.H.; Liu, N.Y.; Tang, Z.S.; Liu, J.; Yang, W.C. Arabidopsis GLUTAMINE-RICH PROTEIN23 is essential for early embryogenesis and encodes a novel nuclear PPR motif protein that interacts with RNA polymerase II subunit III. Plant Cell 2006, 18, 815-830. [CrossRef]

41. Hammani, K.; Gobert, A.; Hleibieh, K.; Choulier, L.; Small, I.; Giegé, P. An Arabidopsis dual-Localized pentatricopeptide repeat protein interacts with nuclear proteins involved in gene expression regulation. Plant Cell 2011, 23, 730-740. [CrossRef] [PubMed]

42. McCarty, D.R.; Settles, A.M.; Suzuki, M.; Tan, B.C.; Latshaw, S.; Porch, T.; Robin, K.; Baier, J.; Avigne, W.; Lai, J.; et al. Steady-state transposon mutagenesis in inbred maize. Plant J. 2005, 44, 52-61. [CrossRef] [PubMed]

43. Tan, B.C.; Chen, Z.; Shen, Y.; Zhang, Y.; Lai, J.; Sun, S.S. Identification of an active new mutator transposable element in maize. G3 (Bethesda) 2011, 1, 293-302. [CrossRef] [PubMed]

44. Sun, F.; Wang, X.; Bonnard, G.; Shen, Y.; Xiu, Z.; Li, X.; Gao, D.; Zhang, Z.; Tan, B.C. Empty pericarp7 encodes a mitochondrial E-subgroup pentatricopeptide repeat protein that is required for $c c m F_{N}$ editing, mitochondrial function and seed development in maize. Plant J. 2015, 84, 283-295. [CrossRef] [PubMed]

45. Li, X.J.; Zhang, Y.F.; Hou, M.; Sun, F.; Shen, Y.; Xiu, Z.H.; Wang, X.; Chen, Z.L.; Sun, S.S.; Small, I.; et al. Small kernel 1 encodes a pentatricopeptide repeat protein required for mitochondrial nad 7 transcript editing and seed development in maize (Zea mays) and rice (Oryza sativa). Plant J. 2014, 79, 797-809. [CrossRef] [PubMed]

46. Sun, F.; Zhang, X.; Shen, Y.; Wang, H.; Liu, R.; Wang, X.; Gao, D.; Yang, Y.Z.; Liu, Y.; Tan, B.C. The pentatricopeptide repeat protein EMPTY PERICARP8 is required for the splicing of three mitochondrial introns and seed development in maize. Plant J. 2018, 95, 919-932. [CrossRef] [PubMed]

47. Acin-Perez, R.; Fernandez-Silva, P.; Peleato, M.L.; Perez-Martos, A.; Enriquez, J.A. Respiratory active mitochondrial supercomplexes. Mol. Cell 2008, 32, 529-539. [CrossRef]

48. Millar, A.H.; Whelan, J.; Soole, K.L.; Day, D.A. Organization and regulation of mitochondrial respiration in plants. Annu. Rev. Plant Biol. 2011, 62, 79-104. [CrossRef]

49. Chen, X.; Feng, F.; Qi, W.; Xu, L.; Yao, D.; Wang, Q.; Song, R. Dek35 encodes a PPR protein that affects cis-splicing of mitochondrial nad4 intron 1 and seed development in maize. Mol. Plant 2017, 10, 427-441. [CrossRef]

50. Ren, Z.; Fan, K.; Fang, T.; Zhang, J.; Yang, L.; Wang, J.; Wang, G.; Liu, Y. Maize empty pericarp602 encodes a P-type PPR protein that is essential for seed development. Plant Cell Physiol. 2019, 60, 1734-1746. [CrossRef]

51. Ligas, J.; Pineau, E.; Bock, R.; Huynen, M.A.; Meyer, E.H. The assembly pathway of complex I in Arabidopsis thaliana . Plant J. 2019, 97, 447-459. [CrossRef] [PubMed]

52. Zhu, C.; Jin, G.; Fang, P.; Zhang, Y.; Feng, X.; Tang, Y.; Qi, W.; Song, R. Maize pentatricopeptide repeat protein DEK41 affects cis-splicing of mitochondrial nad4 intron 3 and is required for normal seed development. J. Exp. Bot. 2019, 70, 3795-3808. [CrossRef] [PubMed]

53. Ren, R.C.; Wang, L.L.; Zhang, L.; Zhao, Y.J.; Wu, J.W.; Wei, Y.M.; Zhang, X.S.; Zhao, X.Y. DEK43 is a P-type PPR protein responsible for the cis-splicing of nad4 in maize mitochondria. J. Integr. Plant Biol. 2020, 62, 299-313. [CrossRef] [PubMed]

54. De Longevialle, A.F.; Meyer, E.H.; Andres, C.; Taylor, N.L.; Lurin, C.; Millar, A.H.; Small, I.D. The pentatricopeptide repeat gene OTP43 is required for trans-splicing of the mitochondrial nad1 intron 1 in Arabidopsis thaliana. Plant Cell 2007, 19, 3256-3265. [CrossRef] 
55. Karpova, O.V.; Kuzmin, E.V.; Elthon, T.E.; Newton, K.J. Differential expression of alternative oxidase genes in maize mitochondrial mutants. Plant Cell 2002, 14, 3271-3284. [CrossRef]

56. Toda, T.; Fujii, S.; Noguchi, K.; Kazama, T.; Toriyama, K. Rice MPR25 encodes a pentatricopeptide repeat protein and is essential for RNA editing of nad5 transcripts in mitochondria. Plant J. 2012, 72, 450-460. [CrossRef]

57. Brangeon, J.; Sabar, M.; Gutierres, S.; Combettes, B.; Bove, J.; Gendy, C.; Chétrit, P.; Des Francs-Small, C.C.; Pla, M.; Vedel, F.; et al. Defective splicing of the first nad4 intron is associated with lack of several complex I subunits in the Nicotiana sylvestris NMS1 nuclear mutant. Plant J. 2000, 21, 269-280. [CrossRef]

58. Barkan, A. Intron splicing in plant organelles. Mol. Biol. Biotechnol. Plant Organelles 2004, 11, $295-322$.

59. Brown, G.G.; Colas des Francs-Small, C.; Ostersetzer-Biran, O. Group II intron splicing factors in plant mitochondria. Front. Plant Sci. 2014, 5, 35. [CrossRef]

60. Chen, Z.; Wang, H.C.; Shen, J.; Sun, F.; Wang, M.; Xu, C.; Tan, B.C. PPR-SMR1 is required for the splicing of multiple mitochondrial introns, interacts with Zm-mCSF1, and is essential for seed development in maize. J. Exp. Bot. 2019, 70, 5245-5258. [CrossRef]

61. Shen, Y.; Li, C.; McCarty, D.R.; Meeley, R.; Tan, B.C. Embryo defective12 encodes the plastid initiation factor 3 and is essential for embryogenesis in maize. Plant J. 2013, 74, 792-804. [CrossRef] [PubMed]

62. Zhang, Y.F.; Hou, M.M.; Tan, B.C. The requirement of WHIRLY1 for embryogenesis is dependent on genetic background in maize. PLoS ONE 2013, 8, e67369. [CrossRef] [PubMed]

63. Wang, X.M.; Chang, N.; Bi, Y.R.; Tan, B.C. Measurement of mitochondrial respiration rate in maize (Zea mays) leaves. Bio-Protocol 2015, 5, e1483. [CrossRef]

64. Meyer, E.H.; Tomaz, T.; Carroll, A.J.; Estavillo, G.; Delannoy, E.; Tanz, S.K.; Small, I.D.; Pogson, B.J.; Millar, A.H. Remodeled respiration in $n d u f s 4$ with low phosphorylation efficiency suppresses Arabidopsis germination and growth and alters control of metabolism at night. Plant Physiol. 2009, 151, 603-619. [CrossRef] [PubMed]

65. Lamattina, L.; Gonzalez, D.; Gualberto, J.; Grienenberger, J.M. Higher plant mitochondria encode an homologue of the nuclear-encoded 30-kDa subunit of bovine mitochondrial complex I. Eur. J. Biochem. 1993, 217, 831-838. [CrossRef] [PubMed]

66. Kumar, S.; Stecher, G.; Tamura, K. MEGA7: Molecular evolutionary genetics analysis version 7.0 for bigger datasets. Mol. Biol. Evol. 2016, 33, 1870-1874. [CrossRef] 